\title{
Ovarian Mucinous Carcinoid Tumor
}

National Cancer Institute

\section{Source}

National Cancer Institute. Ovarian Mucinous Carcinoid Tumor. NCI Thesaurus. Code C40015.

A rare carcinoid tumor that arises from the ovary and is characterized by the presence of glands that are lined by cells that contain intracytoplasmic mucin or resemble goblet cells. Pools of mucin, containing glands, may also be present. It may have an aggressive clinical course and it can metastasize to other anatomic sites. 